\title{
TRABALHO FAMILIAR: \\ distribuição desejada do trabalho doméstico e cuidados dos filhos entre cônjuges
}

\author{
M ara Regina Santos da SI LVA ${ }^{a}$, G eisa dos Santos LU Z ${ }^{b}$, \\ $M$ arta Regina CEZAR-VAZc, Priscila Arruda da SILVA d
}

\section{RESUM 0}

0 objetivo deste estudo é investigar a distribuição de trabalho familiar entre cônjuges que possuem vínculo empregatício e filho (s) de até 6 anos. E studo quantitativo desenvol vido com a participação de 92 casais recrutados na popul ação residente em R io $\mathrm{G}$ rande, R io $\mathrm{G}$ rande do Sul. A distribuição desejada do trabal ho doméstico e cuidados dos filhos ocorreram predominantemente como divisão igual, por ambos, embora o cuidado ao(s) filho(s) tenha sido vislumbrado como maior responsabil idade à mul her. A manutenção/ reparação foi subitem de análise do trabal ho doméstico e se destacou como atividade que deveria ser realizada mais pelos homens. Conhecer as mudanças que incidem na família contemporânea per mitirá uma E nfer magem menos excludente eflexível nas ações em E nfermagem com família.

D escritores: Relações familiares. Cônjuges. Enfermagem familiar.

\section{RESUMEN}

E I objetivo de este estudio es examinar la distribución del trabajo familiar entre cónyuges que poseen vínculo de empleo e hijo(s) dehasta seis años. E studio cuanti tativo desar rollado con la participación de 22 pares reclutados en la población residente en Rio G rande, Rio Grande do Sul, B rasil. L a distribución deseada del trabajo doméstico y cuidados a los hijos ocurrió predominantemente como división igual, por ambos, aunque el cuidado de lo(s) hijo(s) se vislumbró como mayor responsabilidad a la mujer. L a manutención/ reparación fue subtema de análisis del trabajo doméstico y se destacó como actividad que debería ser realizada más por los hombres. Conocer las transformaciones que afectan a la familia contemporánea permitirá una E nfermería menos excluyente y flexible en las acciones en E nfermería con la familia.

Descriptores: R elaciones familiares. E sposos. E nfermería de la familia.

Título: T rabajo familiar: distribución deseada del trabajo doméstico y cuidados de los hijos entre cónyuges.

\section{ABST RACT}

This study investigates the desired distribution of family labor between spouses who have jobs and children of 6 years or less. This is a quantitative study developed with the participation of 92 couples living in the city of R io $G$ rande, state of $R$ io $\mathrm{G}$ rande do Sul, B razil. The desired distribution of housew ork and children care is predominantly an equal one, though the woman was seen as more responsiblefor thecare of children. M anagement/ repairing were subitems of thehousew ork analysis, and were considered to be activities that should be mostly done by men. Knowing the changes of contemporary families will allow nursing to be less exclusionary and more flexible in its family nursing actions.

Descriptors: F amiliar relations. Spouses. F amily nursing.

T itle: Family labor: desired distribution of housew ork and childcare betw een spouses.

\footnotetext{
a D outora em Enfermagem, D ocente do Programa de Pós-Graduação em E nfermagem da U niversidade Federal do Rio G rande (F U RG), Rio Grande, Rio Grande do Sul, Brasil.

${ }^{b}$ M estre em Enfermagem, D outoranda pelo Programa de Pós-Graduação em Enfermagem da FURG, Rio Grande, Rio Grande do Sul, Brasil.

'D outora em Enfermagem, D ocente do Programa de Pós-Graduação em Enfermagem da FU RG, Rio Grande, Rio Grande do Sul, Brasil.

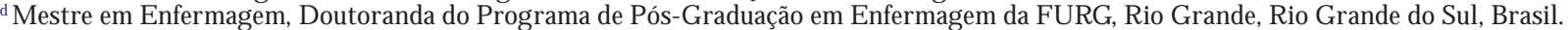




\section{INT RODUÇÃO}

A família contemporânea passou por profundas transformações sociais, políticas, econômicas e culturais nas últimas décadas. 0 avanço do processo de globalização, fenômeno de repercussão mundial, aumentou a competitividade, insegurança no emprego, desigualdade salarial, subemprego, trabalho informal, dentre outros. Para responder as demandas que essa situação aporta à família, a mulher passou a lutar por seu espaço no mercado de trabal ho, condição que alterou as identidades dos sujeitos e possibilitou a reconstrução de novas identidades, principalmente, a respeito dos papéis de gênero na vivência da família(1).

A té o final do século $X X$, a manutenção do equilíbrio entre vida familiar e laboral era realizada através da domesticidade das mulheres, as quais eram excluídas formal e informalmente da vida produtiva ${ }^{(2)}$. Entretanto, as el evadas taxas de desemprego dos homens, somadas às baixas remunerações foram elementos determinantes para a entrada da mulher no mercado de trabal ho assalariado. A partir de então, a contribuição da mulher como provedora tor nou-se fundamental para 0 aumento e/ ou manutenção dos rendimentos familiares ${ }^{(3)}$.

Estas mudanças incidem sobre a família provocando uma significativa transformação na tradicional divisão sexual do trabalho e nas práticas de conciliação entre vida profissional e familiar, as quais podem ser constatadas, em nível global. Ao mesmo tempo, estabelecem a progressiva substituição do modelo de homem provedor do sustento financeiro da família e mulher cuidadora dos filhos, que durante muito tempo estabeleceu as diretrizes da divisão sexual do trabalho.

N esse contexto, os membros da família enfrentam o desafio de conciliar os contextos do trabalho, da família, da conjugalidade e da esfera pessoal ${ }^{(4)}$. Particularmente, a diferença nas contribuições paternas e maternas em relação ao trabalho doméstico e cuidado do(s) filho(s) são preocupações que permeiam entre os cônjuges empregados e constituem o foco deste estudo.

Inseridas na categoria do trabalho doméstico estão várias atividades, como, por exemplo, limpar e organizar a casa, preparar as refeições, fazer as compras, lavar louças, passar roupas, dentre outras. As atividades de manutenção/ reparação são consideradas neste estudo como parte do trabalho doméstico, incluindo, entre outras, a execução de pequenas reparações, o tratamento das plantas, do carro/ moto/ bicicleta e as questões burocráticas e financeiras. São atividades diárias que demandam disciplina e tempo para executá-las. Já o cuidado dos filhos envolve, além das atividades diárias referidas acima, também o auxílio nas tarefas escolares, transporte para a escola e/ ou outros ambientes como creches, de lazer e recr eação.

I números estudos acerca da variável trabalho doméstico mostram que a participação feminina é maior quando comparada à participação masculina ${ }^{(5,6)}$. De ordem prática, as divisões do trabalho doméstico parecem injustas e pouco colaborativas entre os cônjuges, especialmente quando predomina entre eles a ideia de que a mulher é, privativamente, responsável pelas atividades do lar. No entanto é preciso ressaltar que ainda que muitas mulheres continuem a ser a principal responsável pela realização das tarefas da casa e cuidado dos filhos, é possível observar mudanças significativas no que se refere ao envolvimento masculino nos assuntos relacionados ao espaço doméstico, sobretudo quanto aos cuidados com as crianças(1).

D a mesma forma, observa-se que, muitas vezes, no cotidiano da família, os cuidados dos filhos passam a ser secundários e essa responsabilidade frequentemente é transferida a outros setores sociais, como, por exemplo, a escola. N este caso, sobrecarregando essa instituição e atribuindo-Ihe 0 papel de educador principal da criança, o que tempos atrás competia à família. Dentre os familiares, a literatura mostra a avó como principal membro de apoio quando a questão é o cuidado dos fiIhos $^{(4)}$.

Quando ambos os pais são empregados e os filhos são pequenos, a família adentra em um cenário dinâmico de relações de valores, autoridades e papéis. Os trabalhos domésticos mais o(s) cuidado(s) do(s) filho(s) pequeno(s) podem ser percebidos pelos cônjuges como estressores no relacionamento conjugal. Considerando que 20 a $30 \%$ de crianças até cinco anos possuem distúrbio do sono, o momento de descanso dos cônjuges pode ficar afetado e ser responsável pelo cansaço e pouco rendimento no trabalho familiar e profissional(7). A literatura específica acerca desta temática sugere intervenções de apoio para pais de crianças de primeira e segunda infância, visto que são necessárias tarefas relacionadas a faixas etárias iniciais em higiene, alimentação, transporte e/ ou escolar ${ }^{(8)}$. 
A Enfermagem, como profissão que assiste a família, necessita acompanhar as questões globais que determinam mudanças na dinâmica familiar, para melhor compreender e intervir no sentido da prevenção de conflitos relacionais que interferem na saúde de seus membros. É necessário entender o que se passa no processo de partilha dos trabal hos familiares e, principalmente, a divisão desejada pelos cônjuges, uma vez que, dessa forma, é possível antever estratégias de cuidado à saúde da família e, efetivamente, agir na prevenção e promoção da saúde. Para tanto, faz-se necessário compreender a família inserida em seu espaço vital, focalizando sua dinâmica de funcionamento e os fatores que influenciam no desempenho das responsabilidades parentais e conjugais.

As famílias possuem percepções diferentes quanto às formas de conciliar as demandas da vida familiar e profissional. E ntretanto, isso não significa que sejam compartilhadas de formas igualitária e igual ${ }^{(9)}$. E sta necessidade de conciliar os trabalhos da vida privada e pública consiste em uma área de conflito e, quando há formas diferentes de pensar o trabalho familiar, geralmente isso acarreta sobrecarga para um dos cônjuges.

0 presente estudo objetiva investigar a distribuição desejada de trabalho familiar entre cônjuges que possuem vínculo empregatício e filho(s) de até 6 anos.

\section{MÉT ODOS}

Este artigo está vinculado a um projeto que estuda a conciliação entre a vida familiar e profissional, com ênfase na forma como os casais com fil hos pequenos (até 6 anos) organizam as atividades profissionais e as demandas da vida familiar. T ratase de um estudo iniciado por um grupo de pesquisadores da U niversidade do Porto/ Portugal (FAM W ORK) que vem sendo desenvolvido por grupos de pesquisa de outros países, inclusive o Brasil. Em Rio Grande, Rio Grande do Sul, participaram 92 casais recrutados entre a população geral e selecionados com base nos seguintes critérios: a) ter pelo menos um(a) filho(a) com até 6 anos; b) estarem ambos os cônjuges inseridos no mercado de trabalho; c) residir no município no qual 0 estudo foi realizado; d) expressar a concordância em participar do estudo através da assinatura do Termo de Consentimento Livre e Esclarecido (T CLE).
A região onde residem as famílias que integram este estudo é car acteristicamente marítima, com uma população de aproximadamente 200 mil habitantes, que vive predominantemente da atividade portuária e da pesca. E stá local izada na metade sul do Rio Grande do Sul, região menos desenvolvida do Estado.

Os dados foram coletados através de amplo questionário (ver são feminina e ver são masculina), abordando temas relativos à profissão, divisão de tarefas, vida familiar, estratégias para conciliação, vida pessoal, vida em comum e dados sociodemográficos. A ver são original desse questionário, elaborada em 2003 pelos pesquisadores da U niversidade do Porto, Portugal, foi adaptada em 2006 à realidade local, para resguardar as especificidades sociais, econômicas, políticas e culturais do R io $G$ rande, onde a coleta se encerrou em 2008.

Para este artigo foram utilizadas as questões respondidas por ambos os cônjuges, relativas à distribuição desejada de trabal ho doméstico, incluindo manutenção/ reparação, e ao cuidado aos filhos. Para subsidiar a compreensão das respostas dos pais, foi utilizado, também, um conjunto de quatro questões nas quais os pais expressavam suas concepções pessoais em relação ao trabal ho doméstico, na perspectiva das relações de gênero.

As questões relativas à distribuição de trabalho doméstico e cuidado do(s) filho(s) foram respondidas através de uma escala com variação de três pontos (mais por mim; divisão igual por ambos; mais por ele/ ela. Já, nas questões que abordaram concepções sobre as responsabilidades do homem e da mulher nos âmbitos do trabalho doméstico e mercado de trabalho, a escala era de cinco pontos: 1 (discordo total mente); 2 (discordo); 3 (indeciso); 4 (concordo); e 5 (concordo totalmente). E sse questionário foi aplicado na residência das famílias, em horário previamente agendado, sendo a maioria em finais de semana. Para a análise dos dados foi utilizado o programa Statistical Package for the Social Sciences (SPSS), versão 16.0 .

O estudo foi submetido ao Comitê de Ética da instituição envolvida, tendo sido registrado sob o processo de número 23116.003244/ 2008-16. Foram respeitadas todas as recomendações da Resolução 196/ 96(10), com os casais integrados ao estudo somente após a assinatura do Termo de Consentimento Livre e E sclarecido. 


\section{RESULTADOS}

\section{Caracterização dos sujeitos}

A amostra deste estudo foi constituída pelas infor mações referentes a 92 casais. A idade dos cônjuges variou entre 20 e 59 anos, com predominância na faixa de 20-39 anos. Quanto à escolaridade, o predomínio tanto nos homens (34) quanto nas mulheres (26) era do 20 grau completo. D entre as 92 famílias, 46 (50\%) tinham mais de um fiIho com menos de 6 anos. 0 tempo de convivência entre os casais estava entre 2 e 25 anos.T endo como critério a natureza das relações e das condições de emprego, a ocupação dos cônjuges foi classificada em empregador, autoempregado e empregado(11). As mulheres empregadas totalizaram 71,7\% (66), distribuídas em funções como: 12 professoras (13\%); 12 de serviços gerais/ faxineiras (13\%); oito trabal havam na área de enfermagem (auxiliar, técnica ou enfermeira) $(8,7 \%)$; quatro eram empregadas domésticas (4,3\%); quatro, secretárias (4,3\%); quatro, caixas de comér cio (4,3\%); uma, bal conista $(1,1 \%)$, dentre outras. $N$ a categoria de autoempregado, $26(28,3 \%)$ mulheres se encontravam nesta condição. N esta questão, 16 (17,4\%) mulheres não especificaram sua ocupação no emprego. Os homens empregados totalizaram 54 $(58,7 \%)$, nas funções de: comércio/ atendente, com seis $(6,5 \%)$, quatro professores $(4,3 \%)$, três funcionários públicos federais (3,3\%), três vigilantes $(3,3 \%)$, três motoristas $(3,3 \%)$, dentre outras. A omissão de resposta dos homens na questão foi de $30(32,6 \%)$ respondentes.

\section{D istribuição desejada de trabalho familiar entre cônjuges}

As respostas relativas à divisão desejada de trabal ho doméstico entre os cônjuges mostraram que $73(79,3 \%)$ mulheres e $64(69,6 \%)$ homens desejavam que essa atividade fosse dividida igualmente por ambos. Esta diferença de $10 \%$ entre homens e mulheres se mostra também através da concepção pessoal acerca das responsabilidades entre homens e mulheres em relação ao trabal ho doméstico. Quando perguntados se homens e mulheres deveriam ter as mesmas obrigações no que se refere ao trabalho doméstico, as respostas mostraram concordância em 67 (73\%) das mulheres e $56(61 \%)$ dos homens. 0 desejo que fosse rea- lizado mais pela mulher foi assinalado por 18 $(19,6 \%)$ homens e $14(15,2 \%)$ das mulheres. É significativo registrar que cinco $(5,4 \%)$ mulheres e 10 $(10,8 \%)$ homens concordaram que a participação da mulher deveria ser maior nos trabalhos domésticos (T abela 1).

T abela 1 - Percepção dos cônjuges sobre a distribuição da quantidade desejada de trabalho doméstico. Rio G rande, RS, 2008.

\begin{tabular}{lrrrr}
\hline Distribuição do trabalho & \multicolumn{2}{c}{ M ulheres } & \multicolumn{2}{c}{ Homens } \\
\cline { 2 - 5 } doméstico & $\mathbf{n}$ & \multicolumn{1}{c}{$\%$} & $\mathbf{n}$ & $\mathbf{\%}$ \\
\hline M ais por mim & 14 & 15,3 & 10 & 10,8 \\
Por ambos em partes iguais & 73 & 79,3 & 64 & 69,6 \\
M ais por ele/ ela & 5 & 5,4 & 18 & 19,6 \\
\hline Total & $\mathbf{9 2}$ & $\mathbf{1 0 0 , 0}$ & $\mathbf{9 2}$ & $\mathbf{1 0 0 , 0}$ \\
\hline
\end{tabular}

Outro questionamento relacionado à concepção pessoal tratou da exigência de que as muIheres não façam o trabalho doméstico sozinhas. Dentre as respondentes, 60 (65\%) mulheres e 44 $(47,8 \%)$ homens concordaram totalmente.

$M$ ais uma questão de concepção pessoal foi avaliada ao tratar a mulher como única responsável pelo trabal ho doméstico. D o total de cônjuges, 54 $(58,7 \%)$ mul heres e $38(41,3 \%)$ homens discordaram total mente dessa concepção. $\mathrm{N}$ a escala, com escore de 4 a 5, 17 (18,5\%) homens e $16(17,4 \%)$ mulheres concordaram mais com a afirmação.

E $m$ relação à manutenção/ repar ação ( $T$ abela 2), subitem das atividades real izadas como trabalho doméstico, 44 (47,8\%) homens desejavam essas atividades como igualmente divididas entre os cônjuges; 34 (36,9\%), mais por ele; $14(15,2 \%)$ desejavam que fossem realizadas mais pela mulher. Esses percentuais mostram que essa atividade está mais relacionada ao homem, porém eles esperam um pouco mais de envolvimento das mul her es. Quanto às mulheres, $47(51,1 \%)$ desejavam a divisão igual por ambos, $43(46,7 \%)$ das mulheres gostariam que fosse realizada um pouco mais pelos homens e apenas duas $(2,2 \%)$ consideraram que as atividades de manutenção deveriam ser executadas majoritariamente por elas.

Com relação ao cuidado dos filhos, as respostas mostradas na T abela 3 apontam que $78(84,8 \%)$ mulheres e $70(77,2 \%)$ homens desejavam divisão igual. 0 total de $11(11,9 \%)$ mulheres e $16(17,4 \%)$ homens gostaria de ter maior responsabilidade pelo cuidado do(s) filho(s). 
T abela 2 - Percepção dos cônjuges sobre a distribuição da quantidade desejada de manutenção/ reparação. Rio G rande, RS, 2008.

\begin{tabular}{lrrrr}
\hline D istribuição do trabalho & \multicolumn{2}{c}{ M ulheres } & \multicolumn{2}{c}{ H omens } \\
\cline { 2 - 5 } de manutenção/ reparação & $\mathbf{n}$ & \multicolumn{1}{c}{$\%$} & $\mathbf{n}$ & $\%$ \\
\hline M ais por mim & 2 & 2,2 & 34 & 36,9 \\
Por ambos em partes iguais & 47 & 51,1 & 44 & 47,8 \\
M ais por ele/ ela & 43 & 46,7 & 14 & 15,2 \\
\hline T otal & $\mathbf{9 2}$ & $\mathbf{1 0 0 , 0}$ & $\mathbf{9 2}$ & $\mathbf{1 0 0 , 0}$ \\
\hline
\end{tabular}

T abela 3 - Distribuição dos cônjuges segundo a quantidade desejada decuidado(s) do(s) filho(s). R io G rande, RS, 2008.

\begin{tabular}{lrrrr}
\hline Distribuição do trabalho & \multicolumn{2}{c}{ M ulheres } & \multicolumn{2}{c}{ Homens } \\
\cline { 2 - 5 } de cuidado dos filhos & $\mathbf{n}$ & \multicolumn{1}{c}{$\%$} & \multicolumn{1}{c}{$\mathbf{n}$} & $\%$ \\
\hline M ais por mim & 11 & 11,9 & 5 & 5,4 \\
Por ambos em partes iguais & 78 & 84,8 & 71 & 77,2 \\
M ais por ele/ ela & 3 & 3,3 & 16 & 17,4 \\
\hline T otal & $\mathbf{9 2}$ & $\mathbf{1 0 0 , 0}$ & $\mathbf{9 2}$ & $\mathbf{1 0 0 , 0}$ \\
\hline
\end{tabular}

\section{DISCUSSÃO}

A predominância da idade dos cônjuges deste estudo (20-39 anos) define um perfil de casais jovens, embora, quando analisados separadamente, verifique-se a ascendência de $42(45,6 \%)$ mulheres na faixa etária de $20-29$ anos e 42 (45,6\%) homens na de 30-39 anos.

A introdução das mulheres no mercado de trabalho influenciou, sobremaneira, o convívio familiar. A necessidade de melhor qualidade de vida e independência financeira se configura no panorama atual de conquistas no espaço do trabal ho. E ste auxílio no sustento da casa caracteriza-se pela presença de trabal hos formais e informais, de atividades com e sem registro na carteira de trabal ho ${ }^{(12)}$.

As mulheres deste estudo assumem ocupações voltadas ao perfil de mulher cuidadora: educadora (cuidado à criança), área de enfermagem (cuidado às pessoas), trabal hos domésticos (cuidado à higiene). I sso mostra a persistência do perfil de cuidadora imbuído historicamente nas relações da família contemporânea. N os anos de 1990, apesar da crescente diversidade de cargos ocupados pelas mulheres, o serviço doméstico remunerado ainda era a ocupação principal das brasileiras. N aquele momento, era possível constatar que a participação das mulheres no mercado de trabal ho ainda era vista como atividades de "extensão" do lar, focadas em profissões tradicionais, como de professoras, enfermeiras, costureiras, operárias do setor têxtil e empregadas domésticas ${ }^{(13)}$.

Quando se mediu o nível desejado de trabaIho doméstico ( $T$ abela 1 ) entre os cônjuges deste estudo, destacou-se que as tar efas de limpeza da casa deveriam ser realizadas por ambos os cônjuges, em partes iguais, pelas respostas de $64(69,6 \%)$ homens e 73 (79,3\%) mulheres; mas 18 (19,6\%) homens e $14(15,2 \%)$ mulher es acreditavam que ainda deveriam ser realizadas um pouco mais pelas muIheres.

A mulher é historicamente a maior responsável por administrar a rotina da casa ${ }^{(14)}$. U m estudo, com o objetivo de analisar as relações dos sujeitos com seus espaços de vida familiar, observou que 0 espaço doméstico ainda marca as divisões de gênero, sendo que muitas entrevistadas falaram que seus esposos efilhos às vezes faziam o al moço, arrumavam a casa, mas atribuíam a isso o sentido de ajuda, e não de trabal ho ${ }^{(15)}$.

Os trabalhos domésticos perpassam atividades diárias da casa de limpeza do ambiente, de organização e planejamento dos materiais disponíveis. U ma atribuição considerada como desqualificada e não tida como trabal ho, não remuner ada, o trabaIho doméstico sempre recaiu sobre a mulher, enquanto que as funções no "mundo público", supervalorizadas em troca de remuneração ou salário, eram desenvolvidas pelo homem ${ }^{(15)}$. Percebe-se que, na família contemporânea, ainda há um estranhamento quanto às relações do homem no trabal ho doméstico.

Ainda que perseverem padrões históricos e sociais na família, quando questionadas sobre concepções de vida acerca do trabalho doméstico, as mulheres foram preponderantes nas respostas quanto à responsabilidade/ exigência igual entre homens e mul heres nessa atividade. Porém, as respostas foram similares em duas questões que verificaram o desejo da distribuição do trabal ho doméstico e a concepção pessoal sobre trabal ho doméstico: $14(15,3 \%)$ mulheres desejavam se envolver ainda mais no trabal ho doméstico, e 15 (16,3\%) mulheres concordaram que a mulher é a maior responsável no trabalho doméstico, respectivamente. E ssa questão, ao ser comparada com o desejo dos cônjuges, mostra mais uma vez que a mulher historicamente se impõe como responsável pelo trabalho 
doméstico, muitas vezes limitando a aproximação do homem neste tipo de atividade.

A tividades de manutenção/ reparação, no trabalho familiar, englobam atividades descontínuas e de necessidades pontuais, tais como: pequenas reparações, tratar das plantas, ocupar-se do carro/ moto/ bicicleta, dentre outras. N esta questão (T abela 2), os homens demonstraram-se bem distribuídos, ao sel ecionarem a resposta: $44(47,8 \%)$ afirmar am que as atividades de manutenção/ reparação deveriam ser igualmente divididas entre os cônjuges; em 34 (36,9\%), executadas mais por ele; em $14(15,2 \%)$, mais pel a mulher. Sabe-se que al gumas atividades de manutenção/ reparação estão relacionadas a um esforço físico maior, o que talvez explique a maior proporção de homens envolvidos. E ssa realidade mostra a mulher como um ser frágil e pouco habilitado para realizar algumas funções pertinentes à categoria do trabal ho doméstico (manutenção/ repar ação). Por outro lado, el es esperam um pouco mais de envolvimento das mulheres neste tipo de atividade. Quanto às mulheres, $47(51,1 \%)$ desejavam a divisão igual por ambos, e 43 (46,7\%) pensavam que deveria ser real izada um pouco mais pelos companheiros.

0 cuidado do(s) filho(s) é partilhado na vida dos cônjuges com o mundo do trabal ho e doméstico. Com as mudanças na vida da família, a responsabilidade da educação dos filhos passou ser um desafio.

N este estudo, o cuidado ao(s) filho(s) (T abela 3) evidenciou maior índice de divisão igual entre os cônjuges, com 71 (77,2\%) homens e 78 (84,8\%) mulheres. Com a ausência da mãe no seio familiar, a mulher passou a exigir do esposo a mesma participação na criação dos filhos. 0 homem, por sua vez, começa a desempenhar novos e diferentes papéis junto à família. Cada vez mais, a família estabel ece o surgimento de uma nova concepção de pater nidade mais inter essada pelas questões do lar e muito mais participativa(3). Esta mudança traz pistas para o cuidado de E nfer magem enfocando o homem como ator mais participativo nas decisões sobre a saúde da sua família.E studos mostram que, nas famílias onde ambos cônjuges estão inseridos no mercado de trabalho, os filhos esperam que 0 pai se aproxime ainda mais do ideal deles. Além disso, é comprovado que o envolvimento paterno pode influenciar o desenvolvimento social dos fiIhos. Quanto maior a frequência de comunicação entre pai e filho, e da participação do pai nos cui- dados e nas atividades escolares, culturais e lazer do filho, maior a habilidade social e menor 0 índice de hiperatividade e de problemas de comportamento ${ }^{(16,17)}$.

Entretanto, neste estudo, um grupo de homens e mulheres declarou que o cuidado ao(s) fiIho(s) deveria ser realizado mais pela mulher, com $16(17,4 \%)$ e $11(11,9 \%)$, respectivamente. Esses dados revelam a força do papel da mãe na vida familiar, vislumbrando a figura da mulher com múltiplos papéis - mãe, esposa, dona de casa e profissional para suprir a satisfação do trabal ho familiar. E ssa condição pode ser a válvula propulsora da incidência significativa de mulheres com problemas mentais ${ }^{(16,18)}$. E m contrapartida, a mulher conseguiu avanços ao sair de casa e al cançar o mercado de trabalho, sem abrir mão do casamento e de ser mãe. A construção social da mulher proporcionou voz ativa e autonomia na vida pública, conciliada à vida privada, e apontou a necessidade da participação mais ativa do homem nos cuidados domésticos e aos filhos.

A bordar essas questões no âmbito da enfermagem é fundamental, pois com as intensas modificações relacionadas à família hoje sobre diferentes condições em que, preponderantemente, ambos os pais são ativos no mercado de trabal ho e vivem um tempo em que não apenas a empresa é separada da família, mas, também, a distância entre o espaço público e o espaço privado aumentou consideravelmente. E m consequência, os problemas relacionados com a harmonização entre o trabalho e a família se avolumam para qualquer estrutura familiar, inclusive as monoparentais.

Com 0 advento de novos parâmetros sociais e culturais, e a valorização da mulher no trabal ho profissional, isso pode ter influência nos resultados deste estudo. 0 homem vem assumindo novos papéis na família, suprimindo da história o homem autoritário e incipiente nos trabal hos domésticos e cuidados aos filhos. Este conflito da família contemporânea se mostra como um desafio à E nfermagem no cuidado à saúde da mulher, do homem e da criança que advêm desta nova geração de famílias.

\section{CONSIDERAÇÕES FINAIS}

Com a realização deste estudo, foi possível observar que, de uma forma geral, os dados revelam que a distribuição das atividades realizadas por am- 
bos os pais, em partes iguais, se constituem numa exigência em razão da necessidade de trabal har. As mulheres foram mais insistentes nesta resposta em todas as questões, com diferença de cerca de $10 \%$ a mais do que os homens. I sso revel a a voz da mulher, que solicita ajuda e compreensão por sua nova condição social no mercado de trabalho.

Os cônjuges se deparam com a conciliação do tempo entre o trabalho profissional, tarefas domésticas e cuidados aos filhos pequenos. A condição do trabalho é a menos flexível, uma vez que alimenta a lógica econômica da família. Entretanto, a mulher parece ser, entre os cônjuges, a mais sensível quando se trata do tempo desejado no cuidado ao(s) filho(s), o que, muitas vezes, pode contribuir para a diminuição de carga horária do trabal ho profissional. Q uando a mulher e/ ou o homem são impossibilitados desta reparação em sua vida profissional, outros dispositivos são alcançados para que o cuidado do(s) filho(s) pequeno(s) seja suprido, tais como: creche ou ajuda de familiares, principalmente a avó.

As famílias que participaram deste estudo retrataram a realidade de milhares de brasileiros que buscam alternativas para equilibrar as perdas desta nova conjuntura, e tentam reconstruí-la como membros de uma nova geração, de novos valores, mais distantes da vida familiar e mais próximos ao cotidiano do trabal ho. E sta flexibilidade da família propõe uma E nfer magem mais aberta às questões ecológicas que influenciam as relações na família. Conhecer a distribuição desejada do trabalho familiar entre os cônjuges pode subsidiar a Enfermagem frente às famílias com filhos pequenos onde ambos os pais estão inseridos no mercado de trabalho.

Esse estudo mostrou à realidade local, com vistas a conhecer as estratégias que pais, com fiIhos pequenos de até seis anos, utilizam para conciliar a vida profissional e familiar. Considerando que apesar de serem extremamente importantes ainda são escassos estudos sobre a distribuição desejada de trabalho doméstico e o cuidado aos filhos entre os cônjuges. Enfim, é preciso aprofundar o conhecimento da realidade da família contemporânea para subsidiar ações de enfermagem que auxiliem no enfrentamento das dificuldades para assim proporcionar um cuidado efetivo direcionado a estes profissionais que se desenvolve nesta nova forma de viver em família.

\section{REFERÊ NCIAS}

1 T eykal CM , Rocha-Coutinho M L. 0 homem atual ea inserção da mulher no mercado de trabalho. Psico. 2007;38(3):262-8.

2 Sorj B, Fontes A, M achado D C. Políticas e práticas de conciliação entre família e trabalho no Brasil. Cad Pesqui. 2007;37(132):573-94.

3 Cordeiro M . M ulher, mãe etrabal hadora: breve balanço de recentes políticas de conciliação entre trabalho e vida familiar no Brasil. Ser Soc. 2008;10(23):71-9.

4 L evy L, Jonathan E G. M inha família élegal? A família no imaginário infantil. Estud Psicol. 2010;27(1):49-56.

5 Poeshl G. T rabalho doméstico e poder familiar. A nál Soc. 2000;35(156):695-719.

6 Barrere-M aurisson M A. E mploi, famille et conciliation: comparaisons France - Québec. In: Séminaire A ruc sur la gestion des âges et des temps sociaux; 2009 juin 4-5; M ontréal, Canada. M ontréal: T éluq/ U QA M ; 2009.

$7 \mathrm{M}$ ontgomery $\mathrm{P}, \mathrm{D}$ unne D. Sleep disorders in children. Clin Evid. 2007;2007(pii):2304.

8 A hlborg A, M isvaer N. Perception of marital quality by parents with small children. J Fam N urs. 2009;15 (2):237-63.

9 Wagner A, Predebon J, M osmann C, Verza F. Compartilhar tar efas? Papéis e funções de pai e mãe na família contemporânea. Psicol T eor Pesqui. 2005;21(2): 181-6.

10 M inistério da Saúde (BR), Conselho Nacional da Saúde. N ormas de pesquisa envolvendo seres humanos. Res. CN S 196/96. Bioética. 1996;4 Supl:15-25.

11 Goldthorpe JH. On sociology: numbers, narratives, and the integration of research and theory. Oxford: Oxford U niversity Press; 2000.

12 Peiruche J, Beirão AM . N ovos arranjos familiares: pater nidade, parentalidade e relações de gênero sob o olhar de mulheres chefes de família. Psic Clin. 2007;15(2):57-69.

13 Rodriguez GS. Os direitos humanos das mulheres [ Internet]. Rio de Janeiro: Instituto Eqüit; 2007 [ citado 2008 nov 25]. D isponível em: http:/ / www. equit.org.br/ docs/ artigos/ direitoshumanos.pdf.

14 Bruschini M CA. T rabalho e gênero no Brasil nos últimos dez anos. Cad Pesqui. 2007;37(132):537-72. 
15 Lago M CS, Souza CD, Kaszubowski E, Soares M S. Gênero, gerações e espaço doméstico: trabal ho, casa e família. Paidéia. 2009;19(44):357-66.

16 G oetz ER, Vieira M L. Percepções dos filhos sobre aspectos reais e ideais do cuidado parental. Estud Psicol. 2009;26(2):195-203.
17 Cia F, Barham EJ. 0 envolvimento paterno e o desenvolvimento social e crianças iniciando as atividades escolares. Psicol Estud. 2009;14(1):67-74.

18 Santos A M CC. Articular saúde mental e relações de gênero: dar voz aos sujeitos silenciados. Ciênc Saúde Colet. 2009;14(4):1177-82.
Endereço da autora / Dirección del autor / Author's address:

$M$ ara Regina Santos da Silva

Rua Gen. O sório, s/ nํㅜ 4ํandar 96200-190, Rio G rande, RS E-mail: marare@brturbo.com.br
Recebido em: 26/ 11/ 2010

A provado em: 01/ 02/ 2012 